\title{
Epidimiological studies of different eimerian species and their identification in commercial poultry of southern Punjab, Pakistan
}

\author{
Muhammad Jamshed Khan* \\ Institute of Tropical Agriculture \& Food Security, Universiti Putra Malaysia, Malaysia
}

\begin{abstract}
The poultry industry being the leading industry of Pakistan provides around $30 \%$ of total meat production, $100 \%$ of egg production, 4.8 percent of total value addition of Agriculture sector and accommodating more than 03 billion rupees of yearly circulation. The present Epidimiological study was planned to study the prevalence of various Eimerian species by collect 500 samples (litter, whole chicken intestines and intestinal swabs) from different regions of Southern Punjab- Pakistan. The collected samples were observed by oocyst floatation technique to collect the oocysts which were stored in $2.5 \%$ Potassium dichromate solution at room temperature for sporulation. The sporulated oocysts were counted by Mcmaster Counting method for the detection of various species of coccidian parasites. The 290 out of 500 samples were positive showing $58 \%$ of disease prevalence in the area. The prevalence of Eimeria maxima was $24 \%$ in Multan district while $22 \%$ in district Muzaffar garh. Eimeria acervulina prevalence was $35 \%$ in district Dera Ghazi Khan followed by Eimeria necatrix. The severity of coccidial lesions caused by Eimeria tenella was the worst followed by other Eimerian species.
\end{abstract}

\section{Introduction}

Poultry is considered as the second largest industry of Pakistan. It has been commercialized for the provision of protein in the form of meat (Broilers) and eggs (Layer strains). The layer strains of commercial chicken are considered to provide highly nutritive and delicious quality of table eggs. This sector provides 0.767 million tons of broiler meat and 12.857 millions of eggs annually, contributing 4.8 percent of the value addition by the Agriculture sector [1]. In addition by-products such as litter material, wasted meat particles and poultry offal are the great source of earnings for the producers also. Various bacterial, viral, fungal and parasitic diseases cause huge economical losses in poultry industry. Parasites in general and endoparasites in particular, including protozoan like Coccidia are of great importance for this sector. Coccidiosis is the most prevalent, common and an expensive disease of Poultry sector [2] causing huge economic losses.

Epidemiological studies have been conducted for the prevalence of different species of endoparasites including Coccidiosis [3,4] showing only that almost all of commercial indigenous strains of chicken were infected with them. Different agro-climatic zones influence their prevalence as well [4]. Geo-climatic conditions for southern Punjab are most favourable for the propagation of these parasites. This overall situation leads to lower profitability even with lower supply of quality food items to human population of Southern Punjab. It is estimated that the commercial strains are also heavily infected with other endoparasites like intestinal nematodes, which are causing heavy economic losses. Efforts have been done to prevent the commercial flocks of Chicken from Coccidiosis through developing Vaccines against this disease like CoxAbic [5], chemoprophylaxis [6] and other chemicals including sulphaquinoxaline $[7,8]$. But this disease, Coccidiosis prevails in Poultry sector from last 130 years up till now.
Due to the availability of limited data, on major strains of Coccidia in commercial poultry of strains in Southern Punjab, Pakistan the current study was planned.

The current study was conducted with the objectives to study the prevalence of Eimerian species in commercial poultry of Southern Punjab and to identify them through identification of the spores. The effect of season on the prevalence was also been observed [9-11].

\section{Methodology}

\section{Sample collection}

Five hundred samples including litter samples, whole chicken intestines and intestinal swabs were collected from different regions of Southern Punjab. Various areas in Multan, Dera Ghazi Khan

${ }^{\star}$ Correspondence to: Khan MJ, Institute of Tropical Agriculture \& Food Security, Universiti Putra Malaysia, Malaysia, Tel: +923346739647; Email: mjkhan647@ gmail.com

Special Issue: Nanotechnology: Challenges and Perspectives in Medicine

Dr. Federica Valentini

Department of Sciences and Chemical Technologies

Tor Vergata University

Italy

Maurizio Talamo

Professor

Department of Enterprise Engineering

Italy

Key words: Eimeria, Commercial poultry, Prevalence

Received: March 15, 2019; Accepted: April 15, 2019; Published: April 18, 2019 
and Muzzafar Garh districts of Punjab, Pakistan were selected as representative areas. Litter samples of the top layer, from the representative areas of the chicken house, were gathered.

For intestinal sampling, the entire length of the intestine (duodenum to cloaca), from 5 birds per poultry house (at least), were collected in potassium dichromate in almost air tight containers. These samples were transferred to laboratory located at BZ University, Multan, Punjab, Pakistan. The said intestinal samples were selected from 45 commercial poultry farms regardless of previous coccidiosis problem

\section{Detection of Parasites}

The samples were blended in an ordinary blender to release the unsporolated oocysts. The tissues suspended after grinding were filtered through a fine cloth into a beaker using tooth picks. The chemicals in the filtrate were washed with water through a double layer of mesh sieve into a beaker. About 10-15 ml of filtrate was transferred into centrifuge tubes and was centrifuge at $1200 \mathrm{rpm}$ for 10 minutes. The filtrate solids were centrifuged and collected when settled down. The oocysts were suspended from the pellet in a saturated salt solution by removing the supernatant. The oocysts were obtained by pipetting from the top layer of the fluids. The oocyst suspension was washed three to four times to remove the salt solution. The salt-free oocyst suspension was then stored in $2.5 \%$ potassium dichromate solution at room temperature to sporulate. Three isolates containing the more numerous coccidian parasites were selected for pathologic characterization. The collected oocysts were kept at $4{ }^{\circ} \mathrm{C}$ in $2.5 \%$ potassium dichromate solution. The sporulated oocysts were counted per $1.0 \mathrm{ml}$ of solution using the haemocytometer method.

\section{Statistical analysis}

All data were subjected to ANOVA to observe whether the differences between groups are significant. Differences between means were considered at significance level of $\mathrm{p}<0.05$.

\section{Results}

\section{Positive field samples}

Two hundreds and ninety out of five hundreds samples were positive for presence of Eimeria. All positive litter samples belonged to the broiler houses, the negative litter samples comprised of 10 broilers and 22 layer farms. All the positive litter samples except one originated from Multan region, which is considered as the hottest region of southern Punjab, Pakistan.

\section{Eimeria species}

The different species of Eimeria were present in the field samples collected from various commercial poultry farms. These species were identified by the shape index (100 oocysts were collected from each sample). The total number of six these Eimeria species were as under Table 1.

\section{Discussion}

In the present study, 500 field samples, from different areas of Southern Punjab, were evaluated and it was found that $58 \%$ of the samples were positive with respect to the prevalence of Eimerian species (Table 1). For the presence of Eimerian oocysts and their prevalence, it was estimated that E. acevulina $(21.00 \pm 7.37+)$, E. brunette $(13.00 \pm$ $3.60+)$, E. maxima $\left(19.33 \pm 2.90^{+}\right)$, E. mitis $(13.67 \pm 4.07+)$, E. tenella $\left(15.00 \pm 2.08^{+}\right)$and E. necatrix $(14.66 \pm 1.37+)$ were found in the positive samples. Similar results have been reported by Sharma et al. with an overall prevalence of Eimeria as $39.53 \%$ in Jamu \& Kashmire, and Jadhave et al. with the prevalence of Eimeria spp. as $46.04 \%$ in Aurangabad district of Maharashatra, India. Statistically, there was no significant difference $(\mathrm{p}<0.05)$ in the prevalence of the eimerin species in three districts of southern Punjab, Pakistan. The prevalence of E. acevulina was higher in the region followed by E. maxima, E. tenella, E. necatrix, E. mitis and E. brunette (Table 1).

The presence of Eimeria was higher during winter and Moon soon where as the older flocks were very much affected by the parasites as compared to younger one. More number of birds per farm or higher intensity of flock per farm induced the outbreak of coccidiosis at that farm. The climate of the area including temperature, relative humidity and wind velocity also induced the disease prevalence. Regarding weight gain, chickens infected with isolate 3 had the least weight gain followed by isolate 2 and isolate 1 , in sequence. In the cases of isolate 1 and 2, although they originated from a close geographical region, the difference in weight gain and food intake may be either due to different proportion of identified species or the different pathogenicity of the species present in the isolates (Figures 1-3).

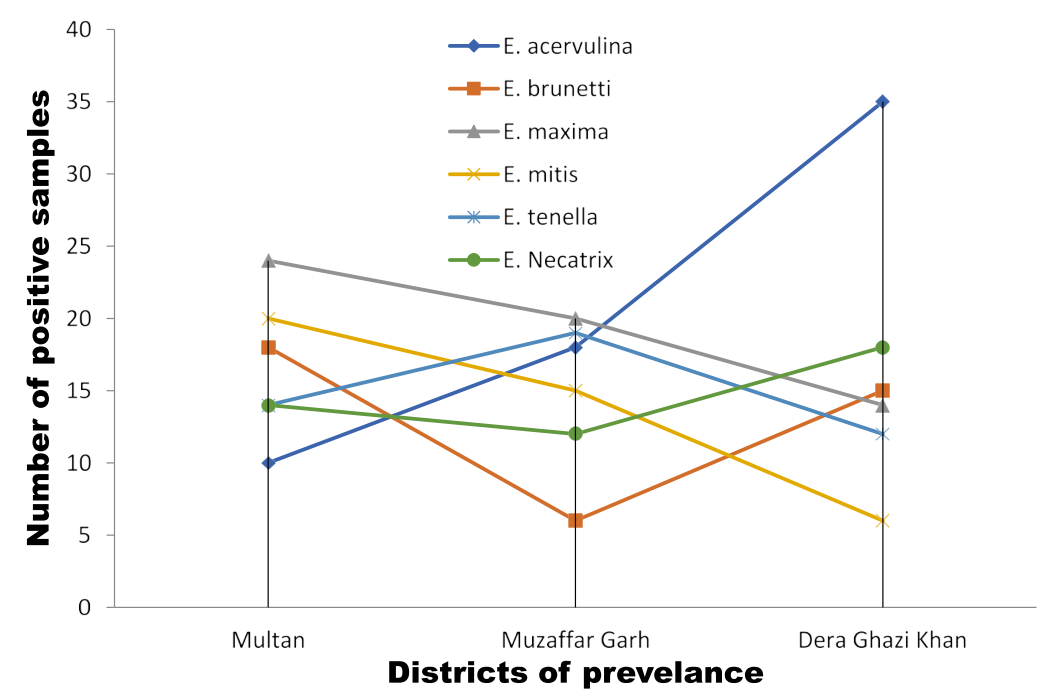

Figure 1. Number of positive samples in different Districts of Southern Punjab, Pakistan 


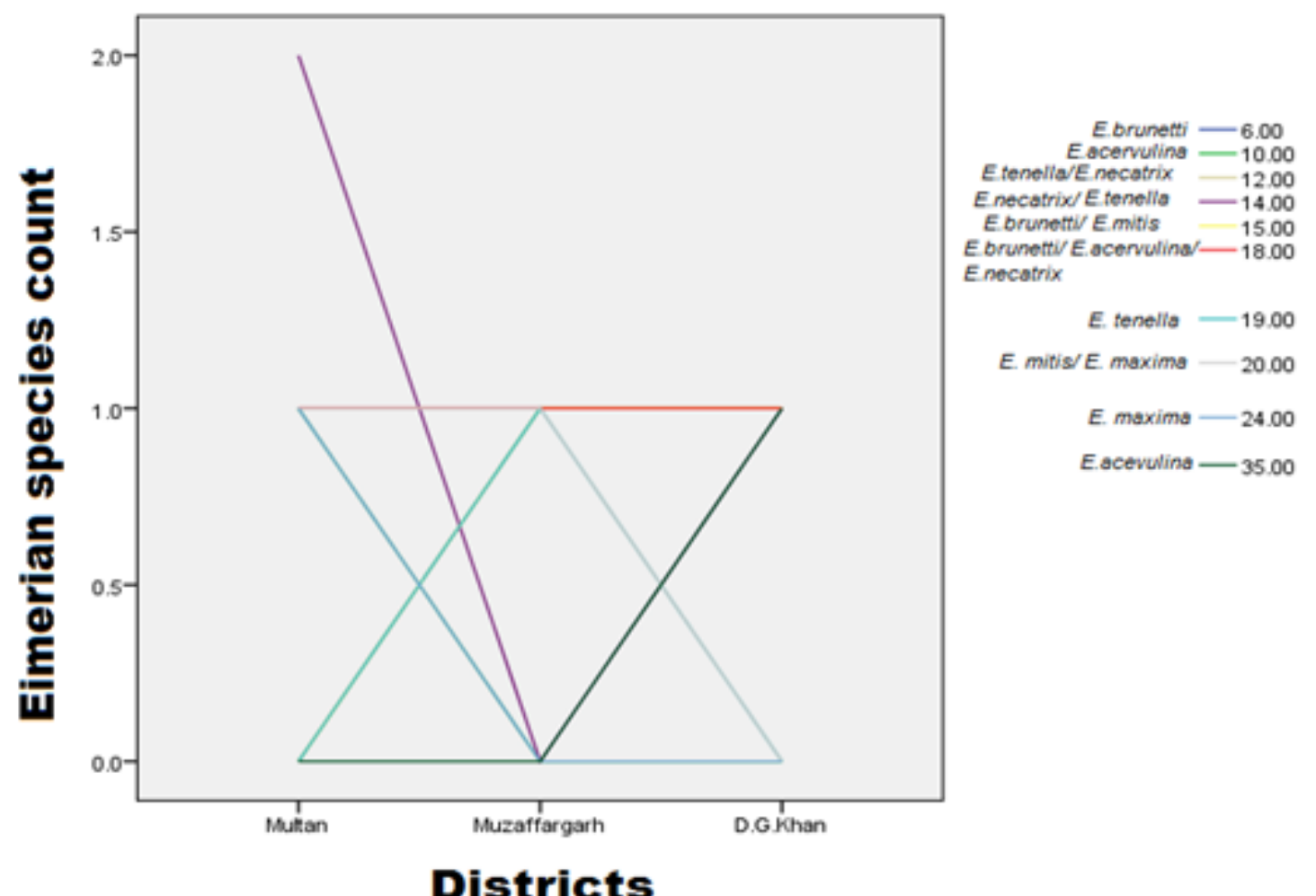

Figure 2. Eimerian species count in different Districts of Southern Punjab, Pakistan
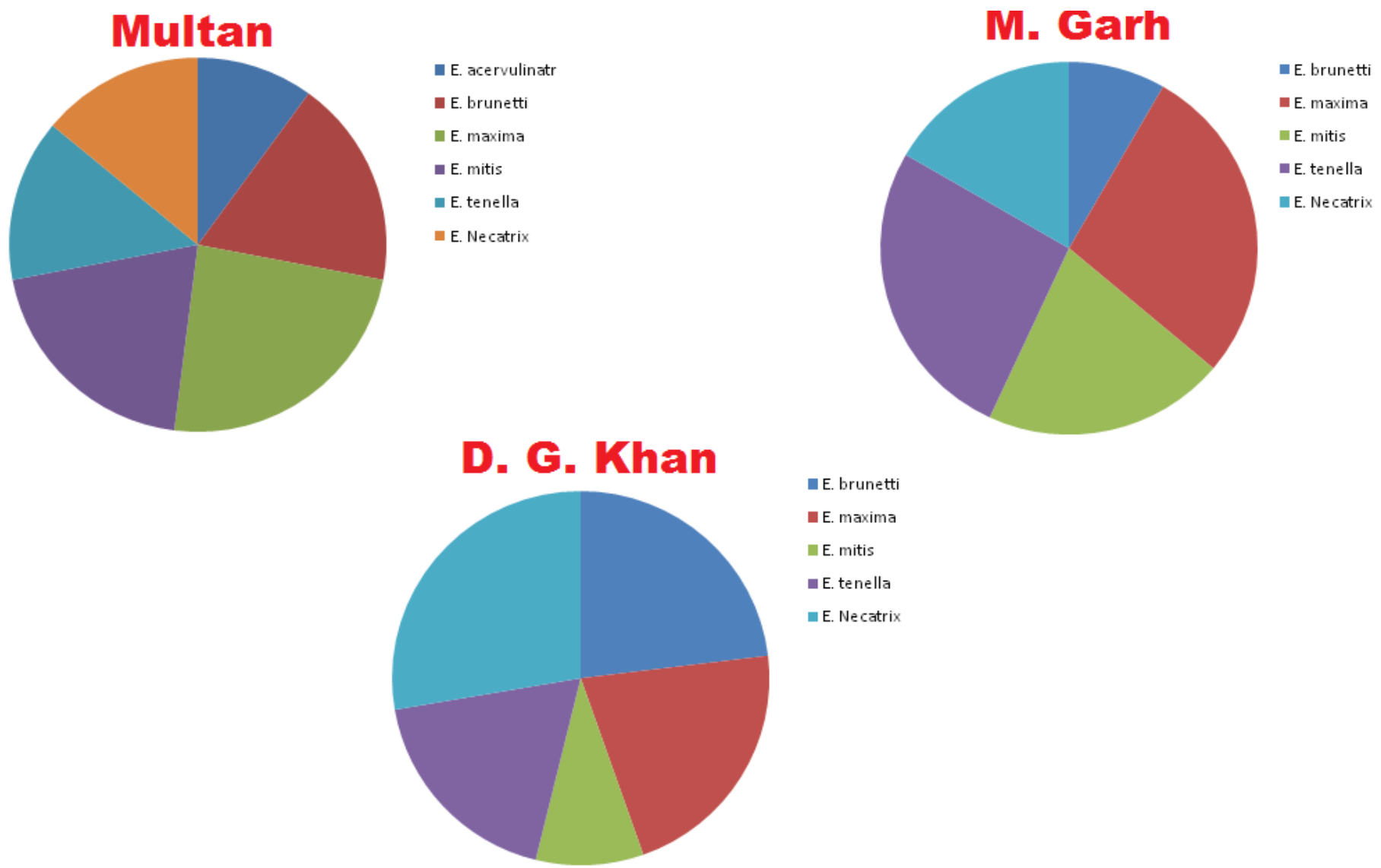

Figure 3. Species wise prevalence in three districts of southern Punjab, Pakistan 
Table 1. Number of positive samples and the means of various Eimerian species in three districts of southern Punjab, Pakistan

\begin{tabular}{|c|c|c|c|c|c|c|c|}
\hline $\begin{array}{c}\text { Region of Southern } \\
\text { Punjab }\end{array}$ & E. acervulina & E. brunetti & E. maxima & E. mitis & E. tenella & E. Necatrix & Total number of samples \\
\hline Multan & 10 & 18 & 24 & 20 & 14 & 14 & 100 \\
\hline Muzaffar Garh & 18 & 6 & 20 & 15 & 19 & 12 & 90 \\
\hline Dera Ghazi Khan & 35 & 15 & 14 & 6 & 12 & 18 & 100 \\
\hline Mean & $21.00 \pm 7.37$ & $13.00 \pm 3.60$ & $19.33 \pm 2.90$ & $13.67 \pm 4.07$ & $15.00 \pm 2.08$ & $14.66 \pm 1.77$ & \\
\hline
\end{tabular}

- Means \pm S.E. of mean.

Grand total of positive sample $=290 / 500(58 \%)$

\section{Conclusions}

The most prevalent species in the two samples collected from Multan district was E. maxima (44 and 34 percent for isolates 1 and 2 respectively) whereas in isolate 3, E. acervulina was more numerous (40\%) present in Dera Ghazi Khan. In Muzzaffar Garh, the most prevalent species was $E$. Tenella. The severity of coccidial lesion caused by isolate 3 was the worst followed by isolates 1 and 2, respectively.

However, E. tenella is considered to have the most pathologic effect, but in the present study, isolate 3, which was the most severe isolate based on all criteria, had the lowest proportion of this species, although the cecal lesion score for isolate 3 was notably higher than the other two isolates which may point out the difference of pathogenicity of Eimeria tenella present in this isolate. Strains of poultry coccidia that vary in pathogenicity have been recognized in various geographical areas. Furthermore, the molecular identification of each isolate, identifying their anti-coccidial drug sensitivity profile, assessing the efficacy of available vaccines against these isolates will be the next steps for providing a basis for coccidiosis research with well-characterized local isolates.

\section{References}

1. Anon (2015) Economic survey of Pakistan Ministry of Food \& Agriculture, Government of Pakistan.
2. Dalloul RA, Lillehoj HS (2006) Poultry coccidiosis: Recent advancements in control measures and vaccine development. Expert RevVaccines 5: 143-163.

3. Somro NM, Rind R, Ariju AG, Somro SA (2001) Clinical, Gross and Histopathological studies of Coccidial Infection in Checken. Int Jour Agri \& Biol 3: 426-427.

4. Kaingu FB, Kibor AC, Shivairo R, Kutima H, Okeno TO, et al. (2010) Prevalence of gastro-intestinal helminthes and coccidia in indigenous chicken from different agroclimatic zones in Kenya. African J Agr Res 5: 458-462.

5. Ziomko I, Karamon J, Cencek T, Gornowics E, Skoracki A, et al. (2005) Prevention of broiler chick coccidiosis using the inactivated subunit vaccine. CoxAbic Bull Vet Intst Pulawy 49: 299-302.

6. Chapman HD (2005) Perspectives for the control of coccidiosis in poultry by chemotherapy and vaccination, Proceedings of IXth International Conference, Foz do Iguassu, 2005.

7. Chapman HD (2003) Origins of coccidiosis research in the fowl--the first fifty years. Avian Dis 47: 1-20. [Crossref]

8. McDougald LR (2003) Coccidiosis, Diseases of Poultry (11th edn), Lowa State University Press Arnes, IA, USA.

9. Sharma S, Iqbal A, Azmi S, Mushtaq I, Wani ZA, et al. (2015) Prevalence of poultry coccidiosis in Jammu region of Jammu \& Kashmir State. J Parasit Dis 39: 85-89. [Crossref]

10. Jadhav BN, Nikam SV, Bhamre SN, Jaid EL (2011) Study of Eimeria necatrix in broiler chicken from Aurangabad district of Maharashtrastate India. Int Multidiscip Res $J 1: 11-12$.

11. Ayaz M, Akhtar M, Hayat CS, Hafeez MA, Haq A (2003) Prevalencen of coccidiosis in broiler chickens in Faisalabad, Pakistan. Pak Vet J 23: 51-52.

Copyright: (C2019 Khan MJ. This is an open-access article distributed under the terms of the Creative Commons Attribution License, which permits unrestricted use, distribution, and reproduction in any medium, provided the original author and source are credited. 